\title{
Mycorrhizal Enhancement of Biomass Productivity of Big Bluestem and Switchgrass in Neutral and Acidic Substrate
}

\author{
Moore, C.V. ${ }^{1}$, E. Kudjo Dzantor ${ }^{1^{*}}$ and D. Hui ${ }^{2}$. \\ ${ }^{1}$ Department of Agricultural and Environmental Sciences and ${ }^{2}$ Department of Biological Sciences, Tennessee State \\ University, 3500 John Merritt Blvd., Nashville Tennessee 37209. USA \\ * Corresponding author: edzantor@tnstate.edu; Tel.: +1 615963 1839; Fax: + 16159631557
}

Original submitted in on 24th March 2015. Published online at www.m.elewa.org on 30th May 2015 http://dx.doi.org/10.4314/jab.v89i1.2

\begin{abstract}
Objectives: Greenhouse pot studies were conducted to assess the abilities of two arbuscular mycorrhizal fungi (AMF) namely, Rhizophagus clarus (Rc) and $R$. intraradices (Ri) to enhance biomass productivity of big bluestem (Andropogon gerardii), as a complementary bioenergy feedstock to and switchgrass (Panicum virgatum).

Methodology and results: Big bluestem (BB) and switchgrass (SG) were grown in a soilless substrate adjusted to $\mathrm{pH}=6.5$ or 4.5 and inoculated separately with $R c$ and $R i$. Plants were grown in the greenhouse for 12 weeks. Results show that AMF significantly enhanced biomass productivity of the grasses over corresponding controls, regardless of $\mathrm{pH}$. Substrate inoculation with $\mathrm{Rc}$ produced the highest and similar total $\mathrm{BB}$ biomass at $\mathrm{pH}=6.5$ and 4.5. However, biomass partitioning into shoot and root differed with $\mathrm{pH}$. Inoculation with Ri produced the highest and similar total SG biomass at $\mathrm{pH}=6.5$ and 4.5. SG biomass was more equally distributed at both $\mathrm{pHs}$. Conclusion and application of findings: Differences in substrate partitioning into shoot and root biomass shown by Rc-inoculated BB at 4.5, appeared to be consistent with Rc endowing BB the capacity to maintain both relatively high shoot as well as root biomass at $\mathrm{pH}=4.5$. This pattern of substrate partitioning was not shown by $R c$ - or $R$ i-inoculated $\mathrm{BB}$ grown at $\mathrm{pH}=6.5$, or $R$ i-inoculated $\mathrm{BB}$ grown at $\mathrm{pH}=4.5$. Neither was the pattern shown by $R c$ - or $R i$-inoculated SG, which maintained relatively similar $\mathrm{R} / \mathrm{S}$ ratios regardless of $\mathrm{pH}$. The usual biomass partitioning by $\mathrm{BB}$ at $\mathrm{pH}=4.5$ deserves further investigation. Different patterns of biomass partitioning notwithstanding, results of this study strongly suggest that BB could complement SG, the model biofuel feedstock, especially under acidic substrate conditions.
\end{abstract}

Key words: Big bluestem; switchgrass; biofuel feedstock; arbuscular mycorrhizae, substrate acidity.

\section{INTRODUCTION}

Heightened global concerns about energy security and environmental sustainability have focused attention on renewable fuels as a means for significantly arresting the world's near-total dependence on finite fossil fuels for transportation. In the US, this focus is largely directed onto biomassto-ethanol conversions. Currently, corn accounts for
94\% of ethanol production (USDA ERS, 2012); however, this is untenable as a long-term proposition. Expansion of corn production to levels needed to meet even a small fraction of the nation's future energy requirements will come with prohibitively steep costs of intensive inputs and associated considerable environmental degradation 


\section{Moore et al. . J. Appl. Biosci. Mycorrhizal Enhancement of Biomass Productivity of Big Bluestem and Switchgrass in Neutral and Acidic Substrate}

(Koo-Oshima, 200). Accordingly, attention has been redirected on warm season perennial grasses WSPGs) for biomass-to-ethanol conversions. The WSPG that has received the greatest attention in the US is switchgrass (Panicum virgatum, L), which, the US Department of Energy (DOE) selected as the bioenergy model, based on such desirable attributes as perennial growth, abundant biomass production, excellent nutrient use efficiency, wide geographic distribution and tolerance to abiotic stressors (Wright \& Turhollow, 2010). With over 30 years of research, a considerable knowledge base exists on the agronomy, management and breeding of SG (Casler et al., 2007). Accordingly, it will continue to play a leading role as feedstock for bioenergy production in the U.S. in the near future. However, in view of the billions of tons biomass that must be produced annually to meet projected biofuel goals (Perlack et al., 2005), it will be necessary not only to greatly enhance the productivity of switchgrass (SG) but also to diversify biomass production by capitalizing on the inherent potentials of other cellulosic biomass crops (Gonzales-Hernandez et al., 2009). Native WSPGs that have been mentioned as complementary feedstock to SG include prairie cordgrass (Spartina pectinata, Bosc ex Link), little bluestem (Schizachyrium scoparium, (Michx.) Nash) (Gonzales-Hernandez et al., 2009), big bluestem (Andropogon gerardii, Vitman) and eastern gamagrass (Tripsacum dactyloides L.) (Anderson et al., 2009; Ge et al., 2012). A distinguishing characteristic among these grasses is their tolerances of soil acidity. For example, Keene and Skousen (2010) found that switchgrass could be successfully established on acid mine land for biofuel biomass production. The same characteristic makes eastern gamagrass valuable for improving acidic subsoils, allowing lands considered marginal or impaired to be put to productive use (Gilker et al., 2002). Acid tolerance by big bluestem has not been systematically studied. Projections made at the emergence of switchgrass as biofuel feedstock had assumed biomass productivity of the grass on prime land. It is increasingly recognized that those earlier projections did not adequately account for the critical issue of land availability. Already, over $30 \%$ of the world's arable land has been affected by acid degradation largely caused by past unsustainable practices (Von Uexkull \& Mutert, 1995). Now, drought and salinity are becoming particularly widespread in many regions, and may cause serious salinization of more than $50 \%$ of all arable lands by the year 2050 (Wang et al., 2003). Not surprisingly, debates over land use for food versus bioenergy have been gaining increasing attention (Ross \& Hinrichs, 2011) as the world's population continues to increase in the face of shrinking prime croplands, increasing energy demands and environmental degradation. Relatively recent reports have suggested that if biofuel feedstocks (low-input high diversity perennials) are planted on abandoned and degraded lands with marginal productivity, an estimated $26-55 \%$ of the current world fuel consumption could be met without affecting crop and forage production (Cai et al., 2011). This is a welcome development but first, it is necessary to enhance biomass production of such marginal lands. One approach for enhancing biomass productivity of marginal lands capitalizes on mycorrhizal symbioses (Ghimire \& Craven, 2011). Mycorrhizal fungi are ubiquitous, obligate soil symbionts that form close associations with plant roots conferring numerous benefits including to nutrient uptake (Smith \& Smith, 2012) and increase tolerance to abiotic stresses on the plant partner (Picardo et al., 2012). This paper reports observations on arbuscular mycorrhizae (AM)-assisted enhancement of biomass productivities of big bluestem in neutral and acidic substrate, using SG as the model biofuel feedstock. Results of the investigations can lead to development of strategies for utilization of acid soils for routine production of alternative biofuel feedstocks. 


\section{MATERIALS AND METHODS}

Plants and growth substrate: 'Alamo' variety of switchgrass (Panicum virgatum L.) and 'Roundtree' variety of big bluestem (Andropogon gerardii Vitman) were obtained from Star Seeds Inc, Osborne, Kansas. Plants were grown on soilless growth substrate composed of peat moss, vermiculite and sand in a 1:1:1 ratio (Al-Agely and Ogram, 2011). Use of soilless medium avoids AMF suppression by high $P$ concentrations characteristic of agricultural soils.

Arbuscular mycorrhizal fungi (AMF): Rhizophagus clarus (formerly Glomus clarum) WV234 and Rhizophagus (formerly Glomus) intraradices, UT125 were obtained from the International Culture Collection of Vesicular Arbuscular Mycorrhizal Fungi (INVAM), Morgantown, WV. Rhizophagus clarus was originally isolated under acidic soil conditions $(\mathrm{pH}<4.0) ; R$. intraradices was isolated from soil at pH 6.5-7.5 (INVAM). Host seed preparation and germination: Seeds of Sorghum bicolor (L.) Moench were surfaced sterilized using a modified Arabidopsis seed sterilization protocol http://www.plantsci.cam.ac.uk/research/jillharrison/protoc ols/arabidopsis/sterilization-arabidopsis-seed.pdf. Briefly, sorghum seeds were washed thoroughly under running water, rinsed with $70 \%$ ethanol for 30 secs, and then treated with $1.0 \%$ of commercial bleach $(5.25 \%$ sodium hypochlorite) containing few drops of Tween 20 . After 15 mins, the seeds were rinsed thoroughly with sterile distilled water 3 times. Surface sterilized seeds were germinated on filter in Petri dishes in the dark for up to 5 days after which time they were transplanted into Deepots (Stuewe and Sons: Tree Seedling Nursery Containers, D40) containing acid washed and autoclavesterilized turface (Pro League $₫$ Calcined Clay).

AMF inoculum propagation and harvesting: Protocols for propagation and harvesting of inoculum were adapted from Giovannetti \& Mosse 1980. Briefly, Deepots were filled with approximately $400 \mathrm{~mL}$ of turface, and then they were overlain by $40 \mathrm{ml}$ inoculum of either Rc or Ri. Each Deepot was covered with additional $60 \mathrm{ml}$ of turface. After planting, seedlings were watered with distilled water every other day. One week after planting, seedlings were watered with a nutrient solution (Peters Professional 150-15 Peat-Lite ${ }^{\circledR}$ Dark Weather Feed), which was supplemented with $0.6 \mathrm{mM} \mathrm{P}$ as $\mathrm{KH}_{2} \mathrm{PO}_{4}$ (Dr Kimberly Gwinn, University of Tennessee personal communication). After four weeks, sorghum roots were sampled to determine the extent of colonization using a Trypan blue staining procedure (Kumar et al., 2008)
Colonization was assessed as counts of propagules (hyphae, vesicles, spores, and arbusculars) using the grid intersection method (Al-Agely \& Ogram, 2011). After 12 weeks, plant feeding was terminated, sorghum shoots were allowed to dry out and mixture of turface containing the propagules was collected, mixed thoroughly and counts of propagules were determined using microscopy (Agley and Ogram, 2011). The mixture was stored at $4^{\circ} \mathrm{C}$ until used for inoculating BB and SG.

Experimental Design: The experiment was conducted in the greenhouse pots ( $1.5 \mathrm{~L}$ capacity) using a factorial design of 2WSPGs $\times 3$ AMF $\times 2 \mathrm{pH}$ where WSPGs were $\mathrm{BB}$ and SG; $\mathrm{AMF}=$ inoculum (Uninoculated, Rhizophagus. clarus, and $R$. intraradices), and 2 levels of $\mathrm{pH}=$ neutral and acidic (6.5 and 4.5). All treatments were replicated four times with four plants per pot. Treatments were arranged in a randomized design on greenhouse benches and they were rotated frequently in order to minimize position effect within the greenhouse.

Adjustment of substrate $\mathrm{pH}$ and WSPG seed pregermination: Substrate $\mathrm{pH}$ was adjusted according to modifications of protocols originally described by Islam et al., (Islam et al., 2004). Instead of $\mathrm{CaCO}_{3}$ used in the original protocol, we used $\mathrm{Ca}(\mathrm{OH})_{2}$ to raise $\mathrm{pH}$ of soilless substrate to 6.5 . The content of peat left the soilless substrate $\mathrm{pH}$ at approximately 4.5 and no further adjustment was needed. Increments of $\mathrm{Ca}(\mathrm{OH})_{2}$ were added to the growth substrate and dose-response curves were generated to allow estimation of amounts of the chemicals required to bring a known amount of substrate to $\mathrm{pH}=6.5(1: 5 \mathrm{w}: \mathrm{V}$ of substrate: $10 \mathrm{mM} \mathrm{CaCl}$ ). Seeds of both $S G$ and $B B$ were initially started in germination trays. After seedlings reached 3 - to 4-leaf stages, they were transplanted into the $1.5 \mathrm{~L}$ pots.

Substrate inoculation, plant growth conditions and harvesting: Seedlings (3- to 4-leaf stage) of switchgrass and big bluestem were inoculated in 5-inch pots containing $1.5 \mathrm{~kg}$ substrate to give propagule concentration $3.9 \times 10^{3}$ and $3.7 \times 10^{3}$ per gram of substrate $R c$ and $R i$ respectively. Plants were grown for 12 weeks. After four weeks, root samples were examined for inoculum colonization as described earlier and the treatments were watered as needed. Once a week, plants were fed with a modified Hoagland's solution (Al-Agley \& Ogram, 2011). At harvest, shoots were cut at $0.5 \mathrm{~cm}$ above the top of the pots dried at $60^{\circ} \mathrm{C}$ and weighed to determine aboveground biomass productivity. Roots were washed to remove substrate materials and they were 


\section{Moore et al. . J. Appl. Biosci. Mycorrhizal Enhancement of Biomass Productivity of Big Bluestem and Switchgrass in Neutral and Acidic Substrate}

dried similarly to determine root biomass productivity of SG and BB.

\section{RESULTS AND DISCUSSION}

These investigations focused on AMF-mediated enhancement of biomass productivity by $B B$ for diversifying biofuel feedstock production especially under abiotic stress conditions such as those imposed by acidity. This is in recognition of the fact that $30-40 \%$ of the world's arable land has been impacted by acid degradation largely caused by past unsustainable practices (Von Uexkull \& Mutert, 1995), and that such lands need to be brought into productive uses in the emerging emphasis on bioenergy. BB was selected for
Statistical Analysis: Mean comparisons of biomass data were made by analysis of variance (ANOVA) using SAS (SAS Institute, 2012).

these investigations because of a number of desirable characteristics. First, it is endemic to North America, which is an important consideration for expanding its production area in the U.S. (Anderson et al., 2008). In addition, Jung \& Vogel (1992) reported that the in vitro fermentability of $B B$ was greater than that for other WSPGs, suggesting that BB may have an advantage over $S G$ when it comes to the production of ethanol and other value-added chemicals via consolidated bioprocessing (Weimer and Springer, 2007).

\section{Rhizophagus clarus}
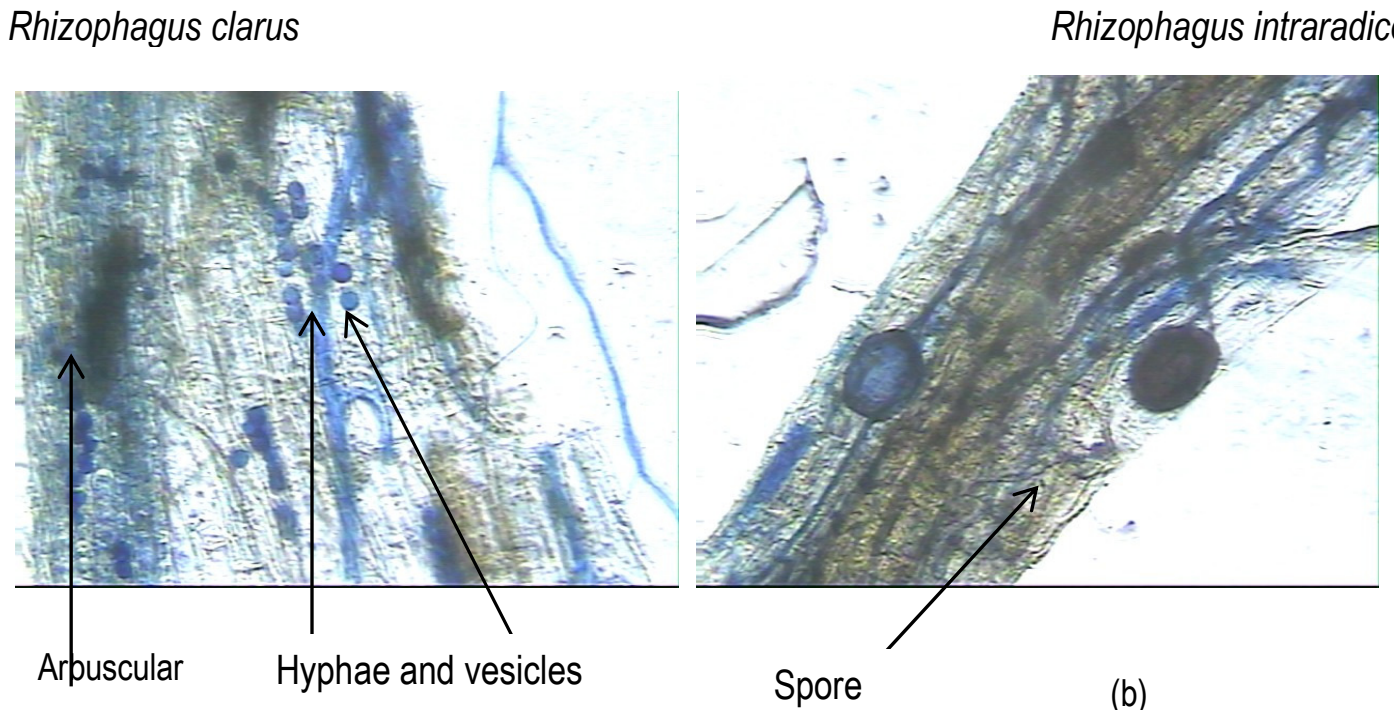

Figure 1: Propagules of (a) $R c$ and (b) Ri used for substrate inoculation
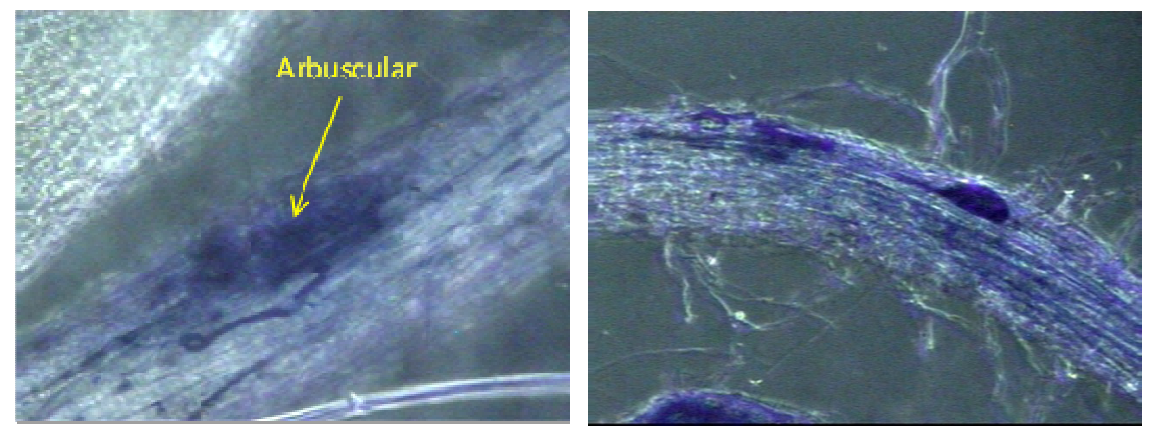

Figure 2: Arbuscular of $R c$ on big bluestem (left) and spore of $R c$ on switchgrass (right).

Propagules (hyphae, arbusculars and spores) of $R c$ and Ri for inoculating BB and SG plants: As mentioned in the 'Materials and Methods', Rhizophagus clarus was originally isolated under acidic soil conditions 


\section{Moore et al. . J. Appl. Biosci. Mycorrhizal Enhancement of Biomass Productivity of Big Bluestem and Switchgrass in Neutral and Acidic Substrate}

$(\mathrm{pH}<4.0) ; R$. intraradices was isolated from soil at $\mathrm{pH}$ 6.5-7.5 (INVAM). Respective inoculums of Rc and Ri were prepared from a 4-month growth of Sorghum bicolor on nutrient solution-fortified turface as described earlier. Figures $1 \mathrm{a}$ and $1 \mathrm{~b}$ are photos of propagules of $R c$ and $R i$ that were used for inoculating the soilless substrate used in these experiments. Figures $2 \mathrm{a}$ and $2 \mathrm{~b}$ are arbuscular of $R c$ on big bluestem and spore of $R c$ on switchgrass during growth of the WSPGs in soilless substrate. AMFmediated enhancement of biomass productivity by big bluestem: Results presented in Table 1 show that at substrate $\mathrm{pH}=6.5$, inoculation with $\mathrm{AM}$ significantly enhanced biomass by BB compared to uninoculated (UN) controls $(p \leq 0.05)$. After 12 weeks, $R c$ - and Ri-inoculated BB produced 3.5 and $3.0 \mathrm{~g}$ dry weight/pot of shoot biomass respectively. This difference was not significant $(p \leq 0.05)$ but it was significantly lower than $0.4 \mathrm{~g} / \mathrm{pot}$ for UN controls (Table 1). Root biomass productivity showed a similar trend to shoot biomass productivity. Thus, substrate inoculation with $R c$ and $R i$ produced similar levels of biomass -7.9 and $7.5 \mathrm{~g} / \mathrm{pot}$, respectively compared to only $0.9 \mathrm{~g} /$ pot for UN controls (Table1).
Thus, substrate inoculation with $R c$ and Ri produced similar levels of biomass -7.9 and $7.5 \mathrm{~g} / \mathrm{pot}$, respectively compared to only $0.9 \mathrm{~g} /$ pot for UN controls (Table1). The ratios of root and shoot biomass productivities (R/S) are shown in Table 1. At $\mathrm{pH}=6.5, \mathrm{R} / \mathrm{S}$ ranged narrowly between 2.25 to 2.50 including that for UN controls. These ratios were useful for the side-by-side comparisons of BB against the model biofuel feedstock, SG. At substrate $\mathrm{pH}=4.5$, the trend of biomass productivity was different from the observation at $\mathrm{pH}=6.5$ (Table 2). At the lower initial $\mathrm{pH} R c$-inoculated $\mathrm{BB}$ produced significantly higher $(p \leq 0.05)$ shoot biomass $(4.2 \mathrm{~g} / \mathrm{pot})$ than that produced by Ri-inoculated BB ( $2.8 \mathrm{~g} / \mathrm{pot})$. Still, the lower shoot biomass of Ri-inoculated $\mathrm{BB}$ was significantly higher than the $0.4 \mathrm{~g} / \mathrm{pot}$ for the control. The contrasting biomass productivity between $R c$ - versus $R i$-inoculated $\mathrm{BB}$ was reflected as significantly higher root biomass of 7.1 /pot compared to $5.0 \mathrm{~g} / \mathrm{pot}$ for Ri-inoculated BB. At the lower $\mathrm{pH}, \mathrm{R} / \mathrm{S}$ ratio for control treatments remained 2.25 , similar to the observation at $\mathrm{pH}=6.5$. However, $\mathrm{R} / \mathrm{S}$ ratio for inoculated treatments declined to 1.69 and 1.79 for $R c$ and $R i$ respectively (Table 2).

Table 1: Effect of AMF Inoculation on Biomass Productivity by Big Bluestem in Neutral Substrate $(\mathrm{pH}=6.5)^{1}$

\begin{tabular}{|c|c|c|c|c|}
\hline Treatment & Shoot & Root & Total & R/S Ratio \\
\hline Uninoculated & $0.4 b$ & $0.9 b$ & $13 b$ & $225 a$ \\
\hline Rhizophagus clarus (Rc) & $3.5 a$ & $7.9 a$ & $11.4 \mathrm{a}$ & $2.26 a$ \\
\hline Rhizophagus intraradices (RI) & $3.0 \mathrm{a}$ & $7.5 \mathrm{a}$ & $10.5 a$ & $2.50 \mathrm{a}$ \\
\hline
\end{tabular}

${ }^{1}$ Values with the same letters in a column are not significantly different $(p \leq 0.05)$.

Table 2: Effect of AMF Inoculation on Biomass Productivity by Big Bluestem in Acidic Substrate $(\mathrm{pH}=4.5)^{1}$

\begin{tabular}{|c|c|c|c|c|}
\hline \multirow[t]{2}{*}{ Treatment } & Shoot & Root & Total & R/S Ratio \\
\hline & \multicolumn{4}{|c|}{ - } \\
\hline Uninoculated & $0.4 \mathrm{c}$ & $0.9 \mathrm{c}$ & $1.3 \mathrm{c}$ & $2.25 a$ \\
\hline Rhizophagus clarus (Rc) & $4.2 \mathrm{a}$ & $7.1 \mathrm{a}$ & $11.3 a$ & $1.69 c$ \\
\hline Rhizophagus intraradices (RI) & $2.8 \mathrm{~b}$ & $5.0 \mathrm{~b}$ & $7.8 \mathrm{~b}$ & $1.79 b$ \\
\hline
\end{tabular}

${ }^{1 /}$ Values with the same letters in a column are not significantly different $(p \leq 0.05)$.

\begin{abstract}
AM-mediated enhancement of biomass productivity by switchgrass: Until recently, WSPG were well known for forage production. Our own research had long focused on their use in phytoremediation of a broad range of organic contaminants (Le et al., 2011; Dzantor et al., 2006; Dzantor \& Woolston, 2001; Dzantor et al., 2000). Appropriate evaluation of $\mathrm{BB}$ as bioenergy feedstock necessitates side-by-side comparison of feedstock attributes against the bioenergy model, SG. Tables 3 and 4 are biomass productivities by SG at substrate $\mathrm{pH}=6.5$
\end{abstract}

and 4.5 respectively. Similar to observations with BB, substrate inoculation AMF significantly enhanced shoot and root biomass productivities by SG compared to the biomass production by corresponding UN controls $(p \leq 0.05)$. The results show that for $\mathrm{SG}$, substrate $\mathrm{pH}$ did not significantly affect shoot or root biomass productivities. After 12 weeks at $\mathrm{pH}=6.5, \mathrm{Rc}$ - and $\mathrm{Ri}$ inoculated $S G$ produced practically identical shoot biomass (4.7 and $4.9 \mathrm{~g} / \mathrm{pot}$, respectively) compared to only $0.6 \mathrm{~g} / \mathrm{pot}$ for the control treatment. Corresponding 


\section{Moore et al. . J. Appl. Biosci. Mycorrhizal Enhancement of Biomass Productivity of Big Bluestem and Switchgrass in Neutral and Acidic Substrate}

root biomass productivities were 5.6 and $6.1 \mathrm{~g} /$ pot for $R c$ and $R$ i-inoculated $S G$ respectively. Differences in these values were not significant $(p \leq 0.05)$. Table 3 shows that at $\mathrm{pH}=6.5, \mathrm{R} / \mathrm{S}$ ratios for control as well as AMFinoculated SG ranged narrowly from 1.00 to 1.27 (Table 3). At $\mathrm{pH}=4.5, \mathrm{Rc}$ and $\mathrm{Ri}$-inoculated SG produced 4.4 and $5.0 \mathrm{~g} /$ pot shoot biomass respectively, compared 1.1 $\mathrm{g} / \mathrm{pot}$ for controls (Table 4). Corresponding root biomass productivities were 5.2 and $6.0 \mathrm{~g} /$ pot respectively. At $\mathrm{pH}$ $=4.5, \mathrm{R} / \mathrm{S}$ ratios ranged even more narrowly from 1.2 to 1.28 for the control and AMF treatments.

Table 3: Effect of AMF Inoculation on Biomass Productivity by Switchgrass in Neutral Substrate $(\mathrm{pH}=6.5)^{1}$

\begin{tabular}{|c|c|c|c|c|}
\hline Treatment & Shoot & Root & Total & R/S Ratio \\
\hline & & g/pot-- & & \\
\hline Uninoculated & $0.6 \mathrm{~b}$ & $0.6 \mathrm{~b}$ & $1.2 b$ & $1.00 \mathrm{a}$ \\
\hline Rhizophagus clarus (Rc) & $4.7 a$ & $5.6 a$ & $10.3 a$ & $1.16 \mathrm{a}$ \\
\hline Rhizophagus intraradices (RI) & $4.8 \mathrm{a}$ & $6.1 \mathrm{a}$ & $10.9 a$ & $1.27 \mathrm{a}$ \\
\hline
\end{tabular}

1/Values with the same letters in a column are not significantly different $(p \leq 0.05)$.

Table 4: Effect of AMF Inoculation on Biomass Productivity by Switchgrass in Acidic Substrate $(\mathrm{pH}=4.5)^{1}$

\begin{tabular}{llccc}
\hline Treatment & Shoot & Root & Total & R/S Ratio \\
& $---1 \mathrm{~b}$ & $1.4 \mathrm{~b}$ & $2.5 \mathrm{~b}$ & $1.28 \mathrm{a}$ \\
\hline Uninoculated & $1.1 \mathrm{~b}$ & $5.2 \mathrm{a}$ & $9.6 \mathrm{a}$ & $1.19 \mathrm{a}$ \\
Rhizophagus clarus $(R c)$ & $4.4 \mathrm{a}$ & $6.0 \mathrm{a}$ & $11.0 \mathrm{a}$ & $1.20 \mathrm{a}$ \\
Rhizophagus intraradices $(R I)$ & $5.0 \mathrm{a}$ & &
\end{tabular}

1/ Values with the same letters in a column are not significantly different $(p \leq 0.05)$.

Overall, results of this study show that substrate inoculation with AMF greatly enhanced total biomass productivity by $\mathrm{BB}$ to levels that are comparable to, or slightly higher than the productivity by SG, the model bioenergy feedstock (Tables 1-4). The results also showed that in general, growth of BB was characterized by greater root biomass productivity than was observed with SG. For example, with the exception of the Riinoculated treatments (which produced only $5.0 \mathrm{~g}$ ) root biomass productivity by BB ranged from 7.0 to $7.9 \mathrm{~g} / \mathrm{pot}$, independent of substrate $\mathrm{pH}$. In contrast, root biomass of AMF-inoculated SG ranged from 5.2 to 6.1 at both $\mathrm{pH}$ levels. Furthermore, Rc-mediated enhanced biomass productivity by BB did not appear to occur at the expense of shoot biomass productivity, a crucial consideration under biomass-to-ethanol bioprocessing. As shown in Table 2, at $\mathrm{pH}=4.5, \mathrm{Rc}$-inoculated $\mathrm{BB}$ produced total biomass of $11.3 \mathrm{~g} / \mathrm{pot}$, which was partitioned into $4.2 \mathrm{~g}$ for shoot biomass and $7.1 \mathrm{~g}$ for root biomass. Under the corresponding conditions, Rc-inoculated SG produced similar level of shoot biomass $(4.4 \mathrm{~g} / \mathrm{pot})$ but only 5.2 $\mathrm{g} /$ pot root biomass (total biomass $=9.7 \mathrm{~g} / \mathrm{pot}$ ). The ratios of root and shoot biomass production (R/S) were useful for the side-by-side comparisons of $\mathrm{BB}$ against the model biofuel feedstock, SG. The manner in which plants partition metabolic production into root and shoot biomass is a topic of ongoing debate (Barbosa et al, 2012; Bonifas and Lindquist, 2006]. Certainly, more studies of the nature described here are needed to provide definitive understanding of the phenomena. However, these results suggest strongly that at least for the purpose of side-by-side comparison, R/S ratios may provide one more measure for evaluating BB and potentially other WSPGs as complementary or alternative feedstock to bioenergy model, SG. A notable aspect of biomass partitioning observed during these experiments was the relatively constant $R / S$ ratios for $S G$ plants $(R / S=1.00$ 1.28) regardless of AMF inoculation or substrate $\mathrm{pH}$. At $\mathrm{pH}=6.5$, BB plants also demonstrated a relatively constant $\mathrm{R} / \mathrm{S}$ ratio $(2.25-2.50)$. However, at $\mathrm{pH}=4.5, \mathrm{R} / \mathrm{S}$ decreased from 2.25 for control to 1.79 and 1.67 for Riand Rc-inoculated $\mathrm{BB}$ respectively. Perhaps more importantly, Rc-mediated relatively high root biomass production was accompanied by relatively high shoot biomass production, similar to the productivity by the SG model. The phenomenon deserves investigation in soil to validate potentials of $R c$-mediated biomass productivity by BB. Previous investigators have reported the use of AMF inoculation to enhance biomass productivity of SG. For example, Clark et al., 2005 studied four AM isolates (Glomus intraradices WV895, G. clarum WV751, G. etunicatum WV579A and Acaluspora mellee) in six acidic 
soil types. They concluded that soil type strongly influenced extent of AMF-mediated enhancement of biomass productivity. The investigations by Clark et al., (2005) are particularly relevant to our own overall goal of developing biomass production systems for diversification of biofuel feedstock (in this case, BB) and production of such feedstock under acidic conditions. Ghimire et al., 2009 and Ghimire and Craven (2011) also reported enhancement of SG biomass productivity of SG following inoculation with the ectomycorrhizae Sebacina vermifera. In the former study, the investigators noted that although S. vermifera was originally isolated from roots of Australian orchids, the association that they created was mutually beneficial. They also expressed caution about the possibility of $S$. vermifera spreading to become infective of weed species. In the later study, the investigators demonstrated ability of $S$. verimifera to enhance biomass productivity under drought conditions. Because of the near total focus on SG as bioenergy feedstock, reports on mycorrhizal mediated enhancement of other WSPGs including BB are very limited. However, some older studies promoted the benefits of $A M$ inoculation to BB biomass production. For example, Hetrick et al., (1990) demonstrated that mycorrhizae improved clipping tolerance of $\mathrm{BB}$, although they cautioned that repeated and intense clipping changed $\mathrm{R} / \mathrm{S}$ ratios and eventually caused the benefits of AMF to be lost. In addition, Bredja et al., (1993) reported that AM inoculation of soils from an eroded site in the Sandhills of Nebraska greatly improved successful reestablishment of WSPGs at this site. In that study, the site was so mycorrhizae-dependent that a 5 -fold $P$ fertilization did not stimulate as vigorous of growth of the grasses as did inoculation with AM. The older reports predated the current emphasis on biofuels; however, they highlight the importance of $\mathrm{AM}$ to the enhancement of biomass productivity in degraded lands. In summary, results of the experiments presented here suggest strongly that $B B$ deserves greater consideration than currently exists, as complementary and/or alternative bioenergy feedstock. In particular, Rc-mediated total biomass production by the grass could be comparable to or slightly higher than production by SG. These experiments were conducted in soilless substrate to avoid depression of AM by levels of $P$ typical of many agricultural soils. Accordingly, this conclusion requires confirmation in soil. Our goal is to enhance biomass productivity in degraded soils, which are typically deficient in P. Side-by-side experiments of the nature described here but in natural soil, are needed to validate AMF-mediated enhancement of biomass productivity by $\mathrm{BB}$ and potentially other WSPGs as biofuel feedstock that can be produced profitably under soil acid and potentially other abiotic stressors.

\section{ACKNOWLEDGEMENT}

This research was partly supported through a grant from the USDA/NIFA (\#2010-38821-21594) awarded to E.K.D.

\section{REFERENCES}

Al-Agely A and Ogram A. 2011. Short course -Soil microbial ecology Mycorrhizal association. University of Florida, Gainesville, FL.

Anderson W, Casler M, Baldwin B. 2009. Improvement of perennial forage species as feedstock for bioenergy. In Vermerris (ed) Genetic Improvement of Bioenergy Crops. Springer Science. Pages 309-345.

Barbosa RI, Silva Dos Santos JR, Souza De Cunha M, Pimentel TP, Fearnside PM, 2012. Root biomass, root: shoot ratio and belowground carbon stocks in the open savannahs of Roraima, Brazilian Amazonia. Australian Journal of Botany, 60:405-416. http://dx.doi.org/10.1071/BT11312.

Bonifas KD, Lindquist JL. 2006. Predicting biomass partitioning to root versus shoot in corn and velvet leaf (Abutilon theophrasti). Weed Sci. 54:133-137.

Bredja JJ, Yocom DH, Moser LE, Waller SS, 1993. Dependence of 3 Nebraska Sandhills warm season grasses on vesicular-arbuscular mycorrhizae. J. Range Manage. 46:14-20. Cai X, Zhang X, Wang D, 2011. Land availability for biofuel production. Environ. Sci. Technol. 45:334-339.

Casler MD, Vogel KP, Taliaferro CM, Ehlke NJ, Berdhal $\mathrm{JD}$, Brummer EC, Kallenbach RL, West CP, Mitchell RB, 2007, Latitudinal and longitudinal adaptions of switchgrass. Crop Sci. 47:22492260.

Clark RB, Baligar VC, Zobel RW, 2005. Response of mycorrhizal switchgrass to phosphorus fractions in acidic soils. Communications in Soil Science and Plant Analysis. 36:1337-1359. 
Dzantor EK, Long DE, Amenyenu TK, 2006. Use of plant systems for mitigating environmental impacts of pesticides. Pp580-583 In M. Taylor (ed.), Proceedings of the Southern Nurserymen Association Annual Conference. August 9, 20

Dzantor EK and Woolston JE, 2001. Enhancing dissipation of aroclor 1248 (PCB) using substrate amendment in rhizosphere soil. $\mathrm{J}$. Environ. Sci. Health Part A 36:1861-1871.

Dzantor EK, Chekol T, Vough LR, 2000. Feasibility of using forage grasses and legumes for phytoremediation of organic pollutants. J. Environ. Sci. Health Part A 35:1645-1661

Ge X, Green VS, Zhang N, Sivakuma G, Xu J, 2012. Eastern gamagrass as a promising cellulosic feedstock for bioethanol production. Process Biochem., 47: 335-339.

Ghimire SR, Charlton ND, Craven KD, 2009. The mycorrhizal fungus, Sebacina vermifera, Enhances seed germination and biomass production in switchgrass (Panicum virgatum $\mathrm{L}$ ). Bioenerg. Res 2:51-58. 2009.

Ghimire SR and Craven KD. 2011. Enhancement of switchgrass (Panicum virgatum L.) biomass production under drought conditions by the ectomycorrhizal fungus Sebacina vermifera. Applied and Environ. Microbial. 77: 7063-7067.

Gilker RE, Weil RR, Krizek DT, Momen B. 2002. Eastern gamagrass root penetration in adverse subsoil conditions. Soil Sci. Soc. Am. J. 66:931-938.

Giovannetti M and Mosse B, 1980. An evaluation of techniques for measuring vesicular arbuscular mycorrhizal infection in roots. New Phytol. 84: 489-500.

Gonzales-Hernandez JL, Sarath G, Stein JM, Owens V, Gedye K, Boe AA, 2009. Multiple Species approach to biomass production from native herbaceous perennial feedstocks. In Vitro Cell Dev. Biol.-Plant. 45: 267-281.

Hetric BAD, Wilson GWT, Owensby CE, 1990. Mycorrhizal influence on big bluestem rhizome regrowth and clipping tolerance. J Range Manage. 43:286-290.

Islam MA, Milham PJ, Dowling PM, Jacobs BC, Garden DL, 2004. Improved procedures for adjusting soil $\mathrm{pH}$ for pot experiments. Communications in Soil Science and Plant Analysis, 35:25-37.

Jung JG and Vogel KP, 1992. Lignification of switchgrass (Panicum virgatum) and big bluestem (Andropogon gerardii) plant parts during maturation and its effect on fiber degradability. J. Sci. Food Agric. 59,169-176.

Keene T and Skousen J, 2010. Mine soil reclamation with switchgrass for biofuel production. National Meeting of the American Society of Mining and Reclamation, Pittsburgh, PA, June 511 , 2010.R.I. Barnhisel (Ed.) Published by ASMR, 3134 Montavesta Rd., Lexington, KY 40502.

Koo-Oshima S. 2007. Water quality and environmental dimensions in biofuel production. CRIAR International Conference on Linkages between Energy and Water Management for Agriculture in Developing Countries. Hyderabad, India: 2931 Jan. 2007. http://www.iwmi.cRiar.org/ewma/files/papers/Sa sha Koo.pdf

Kumar T, Majumdar A, Das P, Sarafis V, Ghose M, 2008. Trypan blue as a fluorochrome for Confocal laser scanning microscopy of arbuscular mycorrhizae in three mangroves. Biotechnic \& Histochemistry. 83(3-4): 153-159.

Le X, Hui D, Dzantor EK, 2011. Characterizing rhizodegradation of the insecticide bifenthrin in two soil types. J. Environ. Prot. 2:942-946.

Perlack RD, Wright LL, Turhollow RF, Graham RL, Stokes BJ, Erbach DD, 2005. Biomass as feedstock for bioenergy and bioproducts industry. The technical feasibility of a billion-ton annual supply. DOE/GO-102005-2134 ORNL/Tm-2005/66.

Pichardo ST, Su Y, Han FX, 2012. The Potential effects of arbuscular mycorrhizae (AM) on the uptake of heavy metals by plants from contaminated soils. J. Bioremed. Biodeg. 3:e124. doi:10.4172/2155$6199.1000 \mathrm{e} 124$.

Ross AM and Hinrichs CC, 2011. Hope and skepticism: Farmer and local community views on the socioeconomic benefits of agricultural bioenergy. Biomass and Bioenergy, 35:1418-1428. SAS Institute Inc. 9.3. 2012. SAS Campus Drive, Cary, North Carolina 27513, USA.

Smith SE and Smith FA, 2012. Fresh perspectives on the roles of arbuscular mycorrhizal fungi in plant nutrition and growth. Mycologia. 104:1-13. 2012. doi: 10.3852/11-229.

United States Department of Agriculture (USDA) Economic Research Service (Ers). 2012. http://www.ers.usda.gov/data-products/usbioenergy-statistics.aspx 
Von Uexkull HR, Mutert E, 1995. Global extent, development and economic impact of acid soils. Plant and Soil 171: 1-15.

Wang W, Vinocur B, Altman A, 2003. Plant responses to drought, salinity and extreme temperatures: toward genetic engineering for stress resistance. Planta 218:1-14. 2003. DOI 10.1007/s00425003-1105-5.

Weimer PJ, and Springer TL, 2007. Fermentability of eastern gamagrass, big bluestem, and sand bluestem grown across a wide variety of environments. Bioresource Technol. 98: 1615 1621.

Wright $L$ and Turhollow $A, 2010$. Switchgrass selection as a "model" bioenergy crop: A history of the process. Biomass and Bioenergy 34:851-868. 